\title{
Health care and privacy
}

\author{
An interview with Kári Stefánsson, founder and CEO of deCODE Genetics in \\ Reykjavik, Iceland
}

EMBO reports (ER): By identifying genes that cause disease, how do you think that drug development, therapy development and treatment of patients will change in the future?

Kári Stefánsson (KS): There is no question that genetics is going to have a significant impact on the way in which we do medicine in the future. One of its promises is that it will bring us predictive testing whereby we can measure an individual's predisposition to a disease. Today, the principle emphasis in healthcare is on interventional medicine, on treating diseases once they have struck an individual. If we have a battery of tests that can tell us which one of the common diseases you are likely to develop, healthcare will develop methods that will allow an individual to modify his or her lifestyle to diminish the probability that the disease will establish itself.

ER: If you have the information on the personal genetic makeup of people and you know that someone has a higher risk of developing emphysema or lung cancer if he smokes, do you think this will be an incentive to crack down on lifestyle choices?

KS: This is all a question of how society decides it wants to use this information. I don't think it would be particularly bad if society generated incentives for you not to smoke. How far society should go into that, however, is a good question. If society began to exclude people from the healthcare system because they smoked, I think it would be an absolute disaster. I would like to see society become more, not less, tolerant. We should be given as much freedom to be ourselves as possible as long as we do not impinge on others. And I think that being in a position to make an intelligent choice about your lifestyle is a privilege that we should

allow ourselves. I am convinced that once you know what your disease predisposition is, it is going to influence the way in

not a particularly aesthetically pleasing method of contraception, but I still think it is very important that the woman has the

\section{'I am convinced that once you know what your disease predisposition} is, it is going to influence the way in which you lead your life'

which you lead your life. But I am certainly concerned about other uses of

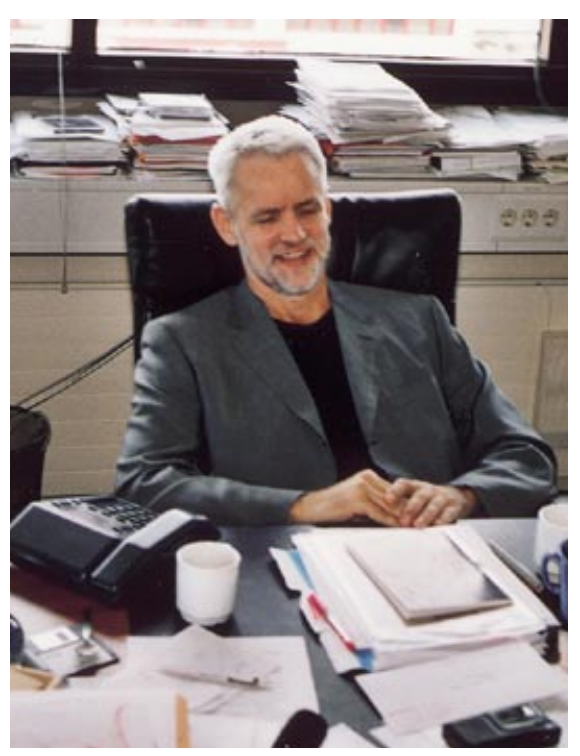

this knowledge. One of the potential ways in which people could use information

'For the moment, the study of variations in the sequence of

DNA is the point of minimum complexity. It is technically very simple and we have the computing power to do it'

from modern genetics is prenatal genetic profiling. I don't like abortion. I think it is right to decide because of the overwhelming social consequences of an unwanted pregnancy. I think, however, that if the woman began to use prenatal genetic profiling to make these decisions, we would be going down a very dangerous path. If the foetus had a high probability of developing diabetes, multiple sclerosis, depression, whatever, and if the woman decided because of that to have an abortion, that would be terrible. If this had been possible 20, 30 or 40 years ago I would not have had the pleasure of meeting most of my friends, because most of them have one or more of these diseases. I think there are all kinds of juggling that society has to do when it comes to choosing how to use information like this. I think that the more knowledge we have, the more opportunity we have to make intelligent choices, and the better society will be. I am absolutely convinced of that.

ER: How will the development of new drugs and therapies change?

KS: So far, the pharmaceutical industry has been looking for proteins that can be influenced by drugs and has then tried to place them in the context of a disease. The discovery of disease genes flips this paradigm around. You begin with a molecule that you know is definitely involved in the disease. Then you determine whether it is 'druggable', and if it isn't, you try to identify its role in a biological pathway that will eventually bring you to a druggable molecule. 


\section{interview}

ER: But that is what genomics, proteomics and other new platform technologies ultimately aim to do as well.

KS: Genetics gives you the point of minimum complexity. With proteomics, you increase the complexity by several orders of magnitude, so I think that before this becomes an alternative for the systematic study of diseases, we have to wait for the computer power to do it. For the moment, the study of variations in the sequence of DNA is the point of minimum complexity. It is technically very simple and we have the computing power to do it. I think that the next revolution in healthcare is going to grow out of the study of nucleotide sequences. Perhaps the following revolution will take place when we are able to systematically study proteomics in the same way as we do genetics today.

ER: So you think classical population genetics will definitely have value for quite a while?

KS: When you're dealing with very complex conditions, like the common diseases, you basically have to do it in a systematic manner. We are currently studying these diseases with very clear, probably often utterly wrong, ideas of what the disease is, what constitutes the disease, and where the margins between two diseases are. But when you look at these diseases unbiased by anything other than the data and the instruments that you have, you uncover fascinating things. One of the stories I can tell you about is our work on the genetics of obesity. Once we had received permission to work on obesity, we simply looked into our database and indeed we had 9000 individuals for whom we had a bmi-body mass index. They had already been genotyped after they had given their informed consent for the study, so it took only a few hours to mark genes that segregate with a bmi over 30. Once we had found this, it became tempting to flip the question around and ask whether there is any gene that segregates with a low bmi. And indeed there was a gene that segregates with a bmi of less than 19. Then we asked the question, what happens if we begin to look at predisposing conditions, such as diabetes. And indeed we were able to map a gene that segregates with adult diabetes in the thin. The reason why this is important is that these alleles cause the disease even in those who have some natural protection. Then we looked at the obese without diabetes because they must also have some protection. Again, we

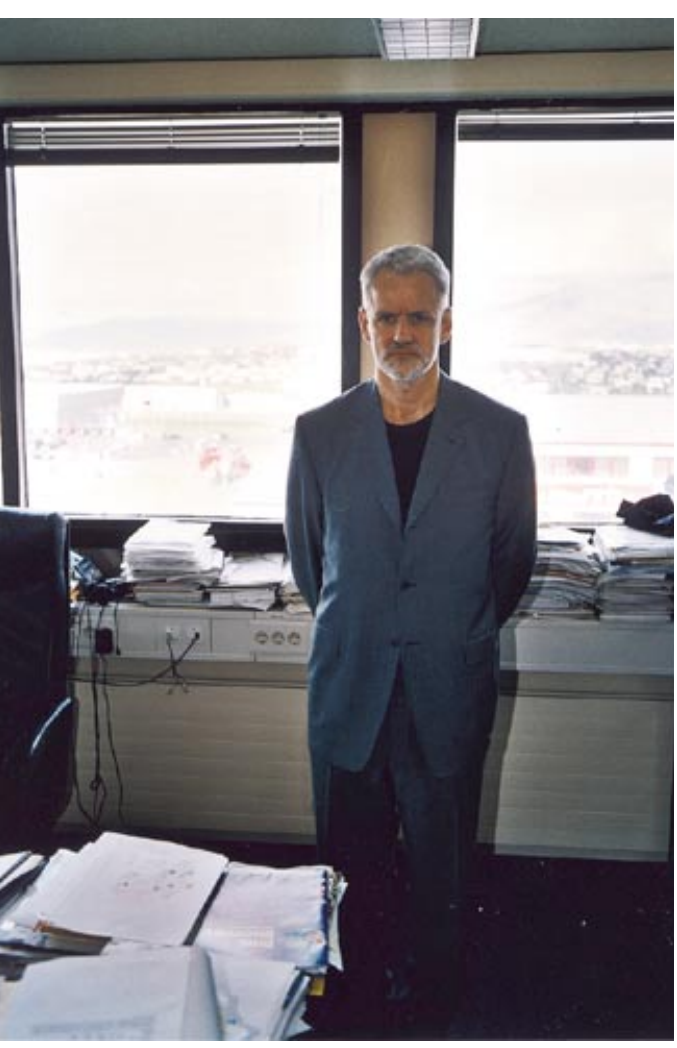

managed to map a gene and it turned out to coincide with the gene that causes diabetes in the thin. So there you have a gene of which one allele causes diabetes while another protects you against it even if you are fat. Normally, this would have taken you 10 years to work out, but we were able to do this in real time because we had the data and the data mining instruments.

ER: But you also have the highly homogeneous Icelandic population to work with, which is a big advantage.

KS: I think that genetic homogeneity is overrated. It helps. But the big advantage we have is the genealogy of the entire nation in a computer database. When you are studying genetics, you are studying information that flows from one generation to the next. Genealogy gives you the

ER: In this context, what do you think of the Estonian approach to establish a similar database not only with genealogical but also with healthcare data?

KS: I think that the concept of gathering healthcare information and matching it with genetic information is a fundamental one, and there is a tremendous need to do this in many places, not only in a homogeneous small nation but also in more heterogeneous ones. Having said that, I think that the challenges the Estonians face are somewhat bigger than ours. First of all, they have only relatively recently had a modern medical system, which means that the quality of the diagnostic data that goes into the database is not going to be quite as good as in our case. Also, they do not have the genealogical data. They can do this but it's going to take them some time. But I think that if they manage to get over these hurdles, they are going to make a great contribution. I hope they will.

ER: I remember Peter Goodfellow saying on several occasions that a centralised healthcare database would be a big step forward in improving healthcare.

KS: What Peter was talking about was the next step in the systematic use of healthcare information, when you begin to implement it. There is no question that healthcare databases would revolutionise

'It is amazing that at the beginning of the 21 st Century healthcare is still all done with the brain of the physician unassisted by any modern informatic instruments'

the quality of healthcare, simply by giving us a tool to help us in decision making. It is amazing that at the beginning of the 21 st Century this is still all done with the brain of the physician unassisted by any modern informatic instruments. When

'When you are studying genetics, you study information that flows from one generation to the next. Genealogy gives you the avenues by which the information flows'

avenues by which the information flows. I think our biggest advantage is that we have access to this information. you go to a bank to withdraw money, that transaction is checked by at least one, if not two, software systems to make sure 


\section{interview}

that it is correct. When you go to see a physician, you put your life in his hands simply because he is a doctor and therefore knows what he's doing. It's absolutely ridiculous. There has to be all kinds of intelligence systems to check on the decision making to make sure we keep a certain standard of healthcare.

ER: But it scares people in Europe and the USA to have their private health data stored, collected and made accessible in large computer banks. KS: I sympathise with this sentiment because I think it is extraordinarily important to have privacy. But let's look at how we deal with other personal information. I have been in about 25 countries this year and in every single country I have been able to withdraw money using my bank card. Why is that? It's because the entire world has now become one universal database

\section{'It is much easier to abuse financial information than healthcare information'}

on personal finance information. It is much easier to abuse financial information than healthcare information. The reason why we have accepted to compromise on the privacy of the most easily abused information is the ease of electronic banking. If you put it in this context, I think it is unreasonable that we should forgo the tremendous advantage that lies in healthcare databases just because of the possibility that someone might abuse it. Let me point out that even if you scour the world you will not be able to find a single example where healthcare information gathered for the purpose of biomedical research has been abused.

ER: How do you convey this to the general public?

KS: Let me give you an example. There are two breast cancer genes that have been discovered. You could find at least 10000 articles written in American newspapers about the possibility that insurance companies will abuse this knowledge. In my mind this would violate two very important rights: one is the right to know, which is considered by our society today as being important knowledge. The second right is the right to equal treatment, irrespective of genetic background. So this basically leads to the question, should

we not have made this discovery because it can be abused? My answer to that is that it would have been criminal if we had

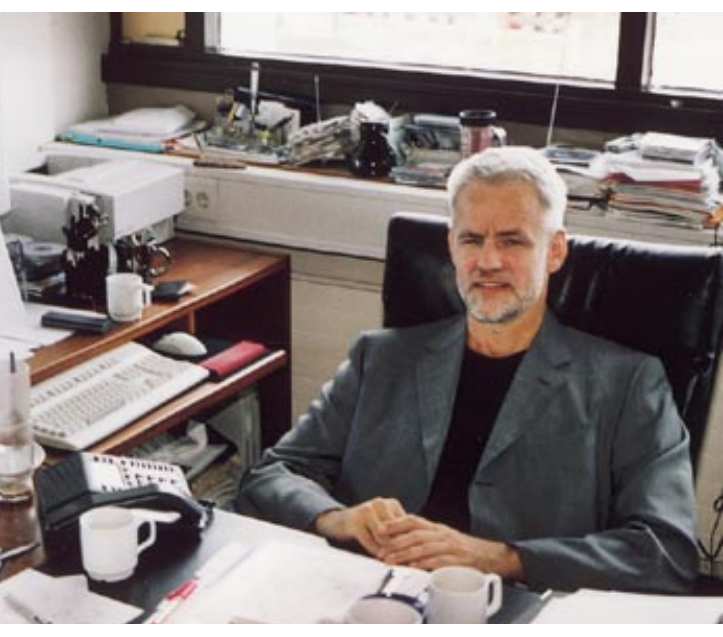

suppressed the discovery of these genes, because they give us insight into the nature of breast cancer and help us to deal with this disease. I think that advocating a ban on the discovery of knowledge is ridiculous. There are potentials for abuse and there will always be people who will abuse knowledge because somehow it seems to lie in our nature.

ER: A breast cancer researcher at Columbia University told me that they have difficulties finding volunteers for their work in the USA because people fear discrimination. So,

'There are potentials for abuse and there will always be people who will abuse knowledge because somehow it seems to lie in our nature'

how should society approach the problem of privacy and potential abuse?

KS: What you are basically talking about is the problem of private health insurance, not a problem with genetic discovery. I personally feel that we should regard access to good healthcare as a human right. Today's healthcare is based on knowledge that was amassed because there were people who allowed information about themselves to be used. The question that automatically arises is

\section{'I personally feel that we} should regard access to good healthcare as a human right'

whether your right to good healthcare should come with an obligation to contribute information about your health, so that good healthcare will be available for your children and their children. In our intense debate on the use of genetics I feel that we in western society are extraordinarily self-centred. It is very interesting to see that the biggest critics of genetics, the biggest critics of the use of healthcare information come from the left and have all of a sudden flipped around the central dogma of socialism in saying that the right of the individual transcends the needs of society. Ethics was a scholarly discipline, but now we have people from universities telling other people what they should do, which I think is dangerous. That is something that society has to do.

ER: How do you explain in this context that in Iceland more than $90 \%$ of the population expressed confidence in deCODE establishing the healthcare database?

KS: You have to look at the history of Iceland. We have always been very societally oriented. If your farm burned down, the adjacent 10 farms were supposed to help you to rebuild the farm. If you lost your sheep, the adjacent 10 farms were supposed to supply you with sheep. The smallness of the society and the short distance between people has created a very strong sense of community. If you talk to the $90 \%$ who sup- port us, a very large proportion of them will say that they are concerned about privacy, but they will tell you that they think the importance of doing this work transcends their concern for the vulnerability of healthcare information. Another point is that Icelanders are passionately interested in history. Why do we have the genealogy of the entire nation in a computer database? Because Icelanders are pathologically obsessed with genealogy and, in their eyes, this healthcare data has been an addition to this.

ER: Most of the criticisms against deCODE's work were based on privacy issues. Now the World Medical Association is drafting guidelines for healthcare databases concerning the protection of privacy.

KS: I think that the WMA genuinely wants to come up with guidelines that will allow research to go on, and that will be 


\section{interview}

acceptable to everyone. We will certainly run our databases in keeping with standards set by institutions such as the WMA. Currently, we are working under Icelandic law under rules that are stricter than you will find anywhere else in the world. I think that the WMA recognises the wisdom of putting together guidelines that allow for the use of these healthcare databases because of the potentials that lie within them. The interest of the patient is first and foremost, to get the best healthcare and not to be dead in the ground with the fullest privacy protection. I think that those who claim that they are fighting for the interests of the patients are adopting a patronising manner in defining what the interests of the patients are, rather than letting them do it for themselves.

KS: I think it is extraordinarily dangerous for the WMA to issue guidelines when it comes to business models. The WMA has a good track record in developing understanding of healthcare, but they have absolutely no track record concerning the economy. I think respect for their guidelines will be diminished if they step outside their established expertise. There are basically three alternatives: governmentrun institutions, non-profit organisations and private business. What are you going to do if the government abuses privacy in a database like this? You cannot close the government. Non-profit organisations are entirely dependent on their ability to raise money, which can be difficult. So basically it would be announced as a nonprofit organisation but in reality it would

\section{'The interest of the patient is first and foremost to get the best healthcare and not to be dead in the ground with the fullest privacy protection'}

ER: The WMA would rather see a nongovernmental, non-profit organisation running a centralised healthcare database. deCODE is certainly not a non-profit organisation. be a branch of the government. And that is fraught with exactly the same problems as when the government does it itself. So why is it dangerous when private companies run things like this? People say that when financial interests are allowed to enter, it distorts reality. But the important point about a private enterprise is that it is very easy to close it. If we violate privacy it takes nothing more than a stroke of the

\section{'If we violate privacy, it takes nothing more than a stroke of the hand from the government to close us'}

pen from the government to close us. What is more, no one would do business with us. So we are controlled by the law, but we are also constrained by the business environment in which we have to survive. I think that if the WMA came out with a recommendation on business arrangements, they would not only become very ineffective but they could also risk becoming a laughing stock.

ER: Dr Stefánsson, thank you for the interview.

The interview was conducted by Holger Breithaupt.

DOI: 10.1093/embo-reports/kve237 